\title{
Miguel A. Yáñez Polo, fotosurrealista metafísico
}

\author{
Miguel B. Márquez \\ (Licenciado en Periodismo. Miembro del Grupo de Investigación en Estructura, \\ Historia y Contenidos de la Comunicación. Universidad de Sevilla)
}

\section{RESUMEN:}

El autor analiza en este artículo la obra fotográfica de uno de los fotosurrealistas más importantes de la actualidad, Miguel Ángel Yáñez Polo. Tras una breve exposición, en la que expone las características básicas del movimiento surrealista, se adentra en los principales rasgos definitorios de la obra de Yáñez, como son la consecución del síntoma de lo fantástico, las técnicas habitualmente empleadas, las continuas referencias a la muerte, los pájaros, el humor, el barroquismo iconográfico y sus planteamientos metafísicos. Concluye el artículo con una aproximación a las últimas corrientes estéticas francesas de la fotografía, cuyos integrantes lo han considerado como uno de los representantes de la no-fotografía.

\begin{abstract}
:
The author analizes the photographic work of Miguel A. Yáñez Polo, one of the most important spanish photosurrealists at this moment. After a brief introduction, who explains the basic characteristics of the surrealist movement, the author describes personal characteristics at the photographic work of Yáñez. Polo: the obtaining of the fantastic symptom, his photographics technics, his constant reference to death, the ominous birds, the humour, the iconographic barrochism and his metaphysicals raisings. This article is ended with an approach to the last french aesthetics currents, whose members consider Yáñez as a representative of non-photographie movement.
\end{abstract}

Palabras claves: Arte/Fotografía/Fotosurrealismo/Fotografía creativa/Surrealismo/Fantástico/Estética.

Key Words: Art/Photography/Photosurrealism/Creative photography/Surrealism/Fantastic-art/Aesthetic.

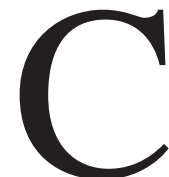

uando nos aproximamos al estudio de la denominada fotografía surrealista, la primera cuestión que nos planteamos es ¿puede la fotografía ser surrealista? y, en caso afirmativo, ¿es que la realidad es surrealista? Tradicionalmente se ha asimilado fotografía con realidad: el saber que eso que vemos ha tenido lugar delante de la cámara, que ha sucedido. Este fenómeno que ya fue suficientemente estudiado por Bazin ${ }^{1}$, es consecuencia del poder ontoló-

1 BAZIN, A. Qu'est-ce que le cinéma? Du Cerf, París, 1975. 
gico de la fotografía y no es extensible a ninguno de los demás medios de expresión, ya sean icónicos o anicónicos. Esto es explicable porque lo que hoy conocemos como fotografía fue un procedimiento buscado durante siglos por los pintores como medio para reproducir lo más fielmente posible la realidad, y este lastre pesa aún sobre el propio medio de expresión. Así pues, podemos comenzar afirmando que la fotografía no es la realidad por cuanto no posee los mismos elementos constitutivos de esa realidad a la que pretende representar. Es más, ni siquiera nos informa acerca de la realidad, sino a lo sumo, de algunos aspectos formales constitutivos de dicha realidad. De ahí que afirmemos que la fotografía es una interpretación analógica del fragmento de la realidad que nos muestra, y eso sólo en el caso de la fotografía que se encuadra dentro del conocido como realismo analógico. Pero cuando el fotógrafo reordena los elementos constitutivos de esa realidad acerca de cuyos aspectos formales nos informa, y lo hace de acuerdo con unos códigos personales, -intencionales o no-, estamos asistiendo a una fotografía que se encuadra dentro del denominado realismo subvertido, estamos contemplando una fotografía surrealista. Este es el engaño o la provocación a la que nos someten todos los fotógrafos surrealistas: al doble juego entre realidad e irrealidad, entre realidad y ficción.

El surrealismo, que pese a lo que diga su fundador, André Breton, es hijo directo del Dadá ${ }^{2}$, no nace, al contrario de lo que sucede en los demás movimientos artísticos, en las artes visuales y luego se extiende a las restantes, sino que lo hace inicialmente como movimiento literario, aunque muy rápidamente se extiende a la pintura, la escultura, el cine y, claro está, a la fotografía ${ }^{3}$. Breton, siquiatra, profundo conocedor de la obra de Sigmund Freud, e influenciado por la misma, considera fundamentales, para el movimiento que nacía, los planteamientos sicoanalíticos freudianos. Por eso da una gran importancia a la locura:

Estoy plenamente dispuesto a reconocer que los locos son, en cierta medida, víctimas de su imaginación, en el sentido que ésta les induce a quebrantar ciertas reglas, reglas cuya transgresión define la calidad de loco, lo cual todo ser humano ha de procurar saber por su propio bien ${ }^{4}$.

...al sueño:

Creo en la futura armonización de estos dos estados, aparentemente tan contradictorios, que son el sueño y la realidad, en una especie de realidad absoluta, en una sobrerrealidad o surrealidad, si así se le puede llamar ${ }^{5}$.

2 BRETON, A. Manifiestos del surrealismo. Labor, Madrid, 1985 (4 ${ }^{\mathrm{a}}$ ed.).

3 Las primeras fotografías surrealistas se publicaron en el $\mathrm{n}^{\circ} 1$ de la revista La Révolution Surréaliste en diciembre de 1924 y estaban realizadas por Man Ray.

4 BRETON, A. Op. cit.: Primer manifiesto.

5 BRETON, A. Op. cit.: Primer manifiesto. 


\section{DIAPOSITIVA}

Sein und zeit: retrato de Chopin.

Clastotipo en color. El clastotipo es un proceso personal de M.A. Yáñez que le permite reordenar la gelatina de la emulsión fotográfica, tras el revelado de la copia. Obsérvese el aspecto tétrico, desolador, de la imagen, en la que no faltan los célebres pájaros. 
... a lo maravilloso:

Digámoslo claramente: lo maravilloso es siempre bello, todo lo maravilloso, sea lo que fuere, es bello, e incluso debemos decir que sólo lo maravilloso es bello ${ }^{6}$.

...a la escritura automática:

En aquel entonces, todavía estaba muy interesado en Freud, y conocía sus métodos de examen que había tenido ocasión de practicar con enfermos durante la guerra, por lo que decidí obtener de mí mismo lo que se procura obtener de aquellos, es decir, un monólogo lo más rápido posible, sobre el que el espíritu crítico del paciente no formule juicio alguno, que, en consecuencia, quede libre de toda reticencia, y que sea, en lo posible, equivalente a pensar en voz alta $^{7}$.

Al igual que ocurriera con otros movimientos artísticos del periodo de entreguerras, el surrealismo se vio arrastrado por el compromiso político, en este caso por el comunismo con el que romperá poco después, ya que veía coartada su libertad de expresión, como se significa claramente en el Segundo Manifiesto:

...en cuanto a mí concierne puedo decir que, hace dos años, no pude, tal como hubiera querido, cruzar libre y anónimamente el umbral de la sede del partido comunista francés, en la que tantos individuos poco recomendables, policías y demás, parecen tener permiso para moverse como don Pedro por su casa. En el curso de tres entrevistas que duraron varias horas me vi obligado a defender al surrealismo de la pueril acusación de ser esencialmente un movimiento político de orientación claramente anticomunista y contrarrevolucionaria. Huelga decir que no tenía derecho a esperar que quienes me juzgaban hicieran un análisis fundamental de mis ideas. Aproximadamente en esta época, Michel Marty vociferaba, refiriéndose a uno de los nuestros: «Si es marxista, no tiene ninguna necesidad de ser surrealista» $^{8}$.

A esta época pertenecen las obras fotográficas de artistas que proceden del campo de la pintura, y cuya obra se encuentra técnicamente a caballo entre esta y la fotografía, como George Grosz, Hanna Höch, Raoul Hausmann y John Heartfied, que venían del movimiento Dadá, pero creadores de unos excelentes collages, -técnica que será casi consubstancial al surrealismo-, Herbert Bayer, Paul Citroën, Heinz Hajek-Halke y Max Ernst. Muchos de estos no se llegan a

6 BRETON, A. Op. cit.: Primer manifiesto.

7 BRETON, A. Op. cit.: Primer manifiesto.

8 BRETON, A. Op. cit.: Segundo manifiesto. 
considerar fotógrafos ${ }^{9}$ porque no han superado los estrechos límites, tanto formales como conceptuales, impuestos por sus propios medios de expresión.

Con el paso de los años, en la década de los cincuenta, y ya superados los vaivenes iniciales, el surrealismo parece orientarse hacia un conocimiento oculto del universo y, si bien pierde buena parte del agresivo y clástico ímpetu inicial, en el aspecto formal progresa extraordinariamente, sobre todo en lo que concierne al surrealismo pictórico. Algo parecido sucede al fotosurrealismo que, una vez rebasadas las experiencias seudosurrealistas de Man Ray y Moholy-Nagy, toma un nuevo auge y se desarrolla con una gran fuerza expresiva. En esta época llevan a cabo su labor fotógrafos como Clarence J. Laughlin, August McBean, Philippe Halsman y Winnifred Casson, aunque este se había mantenido fiel a su línea desde los años treinta.

Pero la fuerza del arte Pop, así como los erróneos manifiestos de la Nueva Subjetividad de Otto Steinert, hacen que el fotosurrealismo pase nuevamente a un segundo plano hasta mediada la década de los setenta en que recobra su pujanza y se asienta definitivamente como una vía de expresión llena de energía. No son ajenos a este resurgir la revista española Nueva Lente, la exposición itinerante que se realizó Fotografía Fantástica Europea y la labor desarrollada por galeristas como el español ya fallecido Albert R. Guspi o el italiano Lorenzo Merlo. Aunque podíamos hablar de un neosurrealismo fotográfico, nosotros nos inclinamos por denominarlo como un tardosurrealismo, que mantiene el aspecto formal de las imágenes, con unos planteamientos oníricos de gran riqueza creativa y enorme fuerza expresiva, superando el compromiso político y buscando otros derroteros de tipo existencial, metafísico, erótico, etc. Es cuando desarrollan sus trabajos fotográficos creadores de la talla de Duane Michals, Antonio Gálvez, Arthur Tress, Henk Meyer, Guy Renaux, Lorenzo Merlo, Paul \& Françoise de Nooijer, Pedro Avellaned, Christian Vogt, Joan Fontcuberta, Serge Lutens, Ange Manganelli, Elías Dolcet, Stane Jagodic, Salvador Obiols, Philippe Sohiez, Jorge Rueda, Timo Huber, Les Krims, Jerry N. Uelsmann y Miguel Ángel Yáñez Polo, estos dos últimos los fotosurrealistas que en mayor grado obtienen en sus obras el síntoma de lo fantástico. A este grupo se han unido, con el discurrir de los años, Ouka Lele, José Carlos Nievas, Eduardo Grund, Francisco Flores Huecas, José de Juan Chirivella y Luis Camacho López de Sagredo, si bien con unos planteamientos que a veces llevan a confundir sus obras con la de los neoexpresionistas fotográficos.

La fotografía surrealista basa su fuerza expresiva en dos técnicas fundamentales para reordenar la realidad: el fotomontaje y el collage, de los que se obtiene lo que los surrealistas han dado en llamar el cadáver exquisito. Hemos de decir, antes de nada, que determinados fotógrafos como Heartfield o Grosz, por sólo

9 El propio Raoul Hausmann lo dijo: Je ne suis pas un photographe, y eso que realizó innumerables fotografías. 
citar dos ejemplos suficientemente conocidos, han sido considerados como fotomontadores por muchos estudiosos en un evidente error, pues son utilizadores del collage, ya que se limitaban a recortar imágenes obtenidas por otras personas, reordenándolas de acuerdo con sus necesidades expresivas y encolándolas, sin preocuparse de corregir los posibles defectos para disimular las pegaduras. Por contra, quienes utilizan la técnica del fotomontaje, tanto si lo hacen mediante el collage directo o refotografiado, como si lo hacen directamente sobre el papel fotosensible, funden los diferentes elementos constitutivos de su obra en un todo perfectamente hilvanado, sin que el espectador pueda reconocer la integración de las distintas imágenes que la componen. Es un matiz que conviene tener muy claro siempre que se hable de las técnicas utilizadas en el fotosurrealismo.

Una de las características que posee el surrealismo, aunque no es exclusiva de él, ni de las artes que se desenvuelven en el espacio bi o tridimensional, es el síntoma de lo fantástico ${ }^{10}$, es lo que Breton denomina lo maravilloso. El fantástico no es un estilo artístico como algunos estudiosos del arte pretenden hacernos creer erróneamente ${ }^{11}$, sino un síntoma definido por tres parámetros perfectamente estudiados como son ${ }^{12}$ :

1. La presentación de la anormalidad como normalidad, dando origen a una nueva realidad que sustituye a la verdadera.

2. La creación de imágenes ambiguas, ocasionalmente no bien definidas, que provocan la duda en el espectador sobre la identidad que representan. Es lo que también se conoce como dualidad iconográfica.

3. El das umheinliche freudiano ${ }^{13}$, productor de un impacto sicológico en el espectador, de una sensación que puede ir de la angustia momentánea hasta una risa espasmódica, defensiva.

Pues bien, en la obra de M. A. Yáñez, estos tres parámetros se producen con una asiduidad tal que podemos considerar al fotógrafo como un surrealista, elaborador de imágenes que producen el síntoma de lo fantástico, sin temor a equivocarnos. Pero el síntoma fantástico no es exclusivo de la fotografía: también se produce en gran parte de la producción pictórica de René Magritte y en muchas de las pinturas de Salvador Dalí, por señalar sólo dos de los pintores más relevantes dentro del surrealismo plástico, que poseen unos planteamientos muy fotográ-

\footnotetext{
10 El síntoma fantástico también se produce mediante la presentación de imágenes directas, es decir, sin manipulaciones, en la obra de muchos expresionistas, y en la literatura (Lovecraft, Sábato) o el cine.

11 Vid. LARKIN, D. Arte Fantástico. Júcar, Madrid, 1973. En la presentación se forma un tremendo galimatías hablando de la fantasía, confundiéndola ¿quizás? con el nombre del libro. La selección de imágenes es bastante certera, aunque existen algunas obras que no producen el síntoma de lo fantástico ni por asomo.

12 Vid. BELEVAN, H. Teoría de lo fantástico. Anagrama, Barcelona, 1976.

13 Se puede traducir al español como extrañeza insólita, extrañeza inquietante, ambigüedad insólita...
} 


\section{DIAPOSITIVA}

3

Juicio de un criador de pájaros.

Clastotipo en color. Una de las características de la fotografía de M.A. Yáñez es su aparición en las imágenes (el personaje de la derecha). El personaje que sobrevuela contrasta con el que se halla arrastrado con una cuerda, lo que provoca una mueca de humor ácido. 
ficos en sus cuadros, tanto en las composiciones como en los encuadres, las perspectivas, etc.

El surrealismo de Miguel A. Yáñez posee unas características muy personales que lo hacen diferenciarse de los demás por dos aspectos esenciales: la técnica utilizada en la elaboración de sus obras y sus planteamientos metafísicos. La técnica básica es de su propia invención, el clastotipo $^{14}$, consistente en un proceso que le permite reelaborar, remodelar, la gelatina fotográfica existente en el papel, de acuerdo con esos planteamientos originarios del surrealismo que en literatura se corresponden con la escritura automática: siempre sé cómo empiezo mis fotografías, pero nunca conozco cómo acabarán -nos ha comentado en más de una ocasión. Es un verdadero in-process discovery ${ }^{15}$, un procedimiento de descubrimiento durante el proceso, en el que el fotógrafo sabe cómo comienza la fotografía y conforme va elaborándola incluye nuevos elementos, imágenes, colores, texturas, elementos ajenos, etc., de modo generalmente inconsciente, y que en un momento dado detiene, considerando concluida su obra. Es una de las principales características de $s u$ expresión aunque alguna de sus obras pueda llegar a considerarse en los límites con el expresionismo fotográfico.

Sus fotomontajes suelen ser de una insultante pulcritud, de ahí que llegue a producir en el espectador con gran facilidad ese das umheinliche que citábamos anteriormente, en un juego onírico de gran profundidad metafísica, donde sus preocupaciones por el hombre ¿qué somos? ¿de dónde venimos? ¿a dónde vamos? forman un continuum casi obsesivo que sobrecoge aún más al receptor de sus imágenes, sin que jamás quede indiferente ante la contemplación de las mismas. Ello se manifiesta en títulos como los que conforman su serie Sein und Zeit, de profunda influencia heideggeriana, con una fuerte carga existencial.

Para conseguir sus propósitos no se acompleja a la hora de introducir, además de las técnicas antes citadas, solarizaciones, tintas, virajes orgánicos o por mordentado, imágenes en negativo, elementos extraños como flores secas o polvos de colores pastel, así como todo aquello que considere conveniente en cada momento ${ }^{16}$, ya que Miguel A. Yáñez, en manifiesta concomitancia con los postmodernistas, está firmemente convencido de que hoy no existen límites entre las artes. Esta es, sin duda, su gran aportación a la evolución del fotosurrealismo.

La muerte es otro de los elementos que no puede faltar en su obra. Siempre está presente, bien mediante frases escritas ad hoc, bien mediante la presencia de

\footnotetext{
14 No sólo utiliza el clastotipo (destructor de la imagen), sino también la ozobromotipia, la bixoftipia dye catalítica, la bixoftipia al argentoviraje y otros muchos procesos inventados por él.

15 Terminología empleada por Peter C. Bunnell en la introducción al libro Jerry N. Uelsmann. Vid. BUNNELL, C. - EDSON, R. Jerry N. Uelsmann. Aperture, New York, 1973.

16 En una fotografía de su serie taurina llegó a incrustar bajo la gelatina unos granos de albero de la plaza de toros de la Maestranza.
} 
ancianos en actitud de espera, de sepulturas... o de pájaros siniestros, introducidos manualmente por el autor, en abundancia tal que producen un enorme agobio en el espectador. Pájaros tétricos, de mal agüero, carroñeros, en actitud agresiva, que parecen querer escapar de sus fotografías para devorarnos a picotazos... Pájaros generalmente inidentificables, aunque en alguna ocasión hemos podido reconocer un pterigodonte ${ }^{17}$, y que son un presagio de la muerte, fruto todos ellos de sus sueños. Unos sueños que en más da una ocasión le han desvelado en medio de una tremenda angustia, y que después quedarán plasmados en muchas de sus imágenes.

La obra surrealista de Miguel A. Yáñez, además de metafísica, puede ser calificarla de barroca dada la gran cantidad de elementos que la inunda, produciendo en el espectador una sensación de caos tremendo, una entropía, en un entorno de cielos lovecraftianos que oscilan entre los violetas del espectro conocido y aquellas otras tonalidades imposibles de describir, pero que percibimos en nuestro subconsciente. Seres que aparecen pero que no están, personajes del ayer como Kant, Beethoven, Schubert, Brahms, el obispo Coloredo, Goethe, Albert Camus, Sigmund Freud, Chopin, Fernando VII, Carlos II 'El Hechizado', Galileo, Cantinflas... en un hoy intemporal, jugando con el tiempo y el espacio de la fotografía, en la que se supone que los tiempos son inciertos. Otras veces nos inunda de fórmulas matemáticas. Y en muchas de sus obras podemos contar con la presencia casi obsesiva del propio fotógrafo en diferentes encuadres dentro de la misma fotografía cual perseguidor que nos atosiga incesantemente. Otras veces contemplaremos caras resquebrajadas, flores vivas/muertas en un difícil equilibrio de realidad/irrealidad... la realidad es un fenómeno imposible de conocer en sí, algo aparente, y cada medio artístico explora la ficción de la realidad fenoménica, comenta Yáñez.

$\mathrm{Y}$ el humor, tan característico del surrealismo, no puede estar ausente en la obra de Miguel Ángel, con títulos elocuentes que nos remiten a su Sevilla natal, a sus costumbres, a sus gentes, a su historia, como Juicio a un criador de pájaros, Retrato de la inventora del Rococó, The Sierpe's Organist, Plañidera en la plaza de toros, Homenaje a la siesta sevillana, Necrománticos de hoy, La idea filtrada, Pensador en la Maestranza, El impoluto hispalense, Recuerdos del moro Muza, Tanguistas metafísicos, Estrangulador de viejas salerosas, Rococó al vitriolo, El existente enmascarado, La flamencona del pajarito, La torera zoomórfica, Trini la salerosa, El presidente Máximo del Tribunal Supremo en calzonas, El sastre marítimo, Semiología de la piompa... Un humor sarcástico, amargo, incisivo, crítico, que mueve más a la reflexión que a la carcajada, consecuencia lógica de esos planteamientos metafísicos a los que aludíamos. Un humor que surge a causa

17 Animal prehistórico, con aspecto de lagarto gigante alado. 
del carácter absurdo de los citados títulos. Y es que ¿habrá algo más surrealista que el absurdo, o algo más absurdo que el surrealismo?

La obra de Miguel A. Yáñez está muy en línea con las actuales corrientes vanguardistas francesas de la estética fotográfica encabezada por François Larue$1 \mathrm{l}^{18}$, quien lo ha señalado como un destacado representante de la no-fotografía, al lado de fotógrafos como Olivier Richon, Jordi Guillaumet, Teun Hocks, Philippe Gully, Robert Suermont, Ouka Lele, Frans van Lent, Marc Gilloux y otros. La nofotografía ${ }^{19}$ no es, como pudiera pensarse, la negación de la fotografía, sino

un proceso más universal que sus descripciones fenomenológicas, sociológicas, sicoanáliticas: estos planteamientos son restrictivos y negativos porque la reducen a la multiplicidad y a la unilateralidad de sus condiciones de existencia en la percepción, la historia, la vida social, etc. Este término debe pues entenderse por analogía con no euclidiano y haciendo de la fotografía una axiomática de la percepción. Laruelle postula la existencia de un pensamiento fotográfico. E interpreta la fotografía como un pensamiento autónomo y original pero ciego, irreflexivo, automático más próximo a la ciencia que a la filosofía.

Esto debió percibirlo Ernesto Sábato, cuando escribió acerca de la obra de Miguel Ángel Yáñez Polo:

...desde esta perspectiva filosófica, la fotografía es más proclive a calcar la realidad exterior, pero puede alejarse, y en rigor se aleja, de esta estúpida reproducción por la potencia creativa del fotógrafo; en la elección del tema, del ángulo, de la luz, de los contrastes. Y alcanza los atributos de un auténtico arte, cuando los elementos de la realidad externa son trastocados, violentados y recombinados por el creador. Así, de este modo espectacular, sucedió con Man Ray y con los collages de Max Ernst. Y así sucede con las propias y admirables creaciones de Yáñez Polo ${ }^{20}$.

$* * * * *$

Miguel Ángel Yáñez Polo nació en la sevillanísima calle de Alfonso XII en 1940. Doctor en Medicina, ex profesor universitario, cultiva la fotografía desde mediados de la década de los setenta. Fundador del Grupo Fotográfico f/8 de Libre Expresión y de la Sociedad de Historia de la Fotografía Española, ha participado en multitud de exposiciones en las principales galerías del mundo entero.

18 Vid. Pour la Photographie tomo III, capítulo V, donde se exponen ampliamente estos planteamientos.

19 ...je parle de non-photographie formule qui doit se prendre évidemment d'un seul bloc. Ce n'est pas la négation de la photographie, c'est une posture descriptive qui intègre les interprétations philosophiques traditionnelles (dont l'idée traditionnelle de pluralité des pratiques photographiques) a l'état de matériau d'une activité non-photographique plus universelle. Pour la Photographie, op. cit.

20 Revista Actas de Cultura y Ensayos Fotográficos f/8. Sevilla, invierno 1981. 


\section{DIAPOSITIVA}

Sein und zeit: retrato de Brahms.

Clastotipo en color. Obra de gran dramatismo y tremendamente barroca, en la que no faltan los pájaros y las alusiones a la muerte con la inclusión de calaveras. 
Su obra se encuentra en los principales museos y colecciones como el Centre d'art Moderne Georges Pompidou de París, Gabinete de Estampas de la Biblioteca Nacional Francesa, Museo de Arte de Palma de Mallorca, Museo Taurino de Córdoba, Museo de Arte Contemporáneo de Sevilla, Fondos fotográficos de la Tucson-Arizona University, Lincoln Center Art de Denver (Colorado, EE.UU.) y Museo Nacional Centro de Arte Reina Sofía de Madrid, entre otros.

Gran teórico de la fotografía, ha pronunciado numerosas conferencias y publicado en las más importantes revistas del medio como Arte Fotográfico, Photovisión, La Fotografía, Actas de Cultura y Ensayos Fotográficos f/8 o Revista de Historia de la Fotografía Española, con temas de pensamiento, estética, historia o técnica. Dirigió el curso Vanguardia fotográfica 2000, celebrado en 1991 en la Universidad de La Rábida. Como literato ha obtenido el premio Blanco White con la obra Kant, amigo mío, y tiene publicadas varias novelas, todas ellas dentro de una línea surrealista muy homogénea, por lo que podemos decir que viendo sus fotografías sabemos cómo escribe, y a la inversa. Desde su sevillano Heliópolis, casi sin moverme de aquí, como él suele decir, continúa inundando el mundo con sus imágenes y con sus pensamientos.

\section{Bibliografía:}

- AA. VV. Pour la photographie. Actes du I colloque international pour la photographie. Germs, París, 1983.

- AA. VV. Pour la photographie. Actes du II colloque international pour la photographie. Germs, París, 1987.

- AA. VV. Pour la photographie III. Germs, París 1990.

- ADES, D. El Dadá y el Surrealismo. Labor, Barcelona, 1975.

- ADES, D. Fotomontaje. Bosch, Barcelona, 1977.

- ÁlVAREZ VILLAR, A. Psicología del arte. Biblioteca Nueva, Madrid, 1974.

- ARGAN, G. C. El arte modeno (2 vols.). Fernando Torres, Valencia, 1977 (3 ${ }^{\mathrm{a}}$ ed.).

- BAZIN, A. Qu'est-ce que le cinéma? Du Cerf, París, 1975.

- BELEVAN, H. Teoría de lo fantástico. Anagrama, Barcelona, 1976.

- BOZAL, V. La construcción de la vanguardia (1850 - 1939). Edicusa, Madrid, 1978.

- BRETON, A. Manifiestos del surrealismo. Labor, Madrid, 1985 (4 ${ }^{\mathrm{a}}$ ed.).

- BUNNELL, C. - EDSON, R. Jerry N. Uelsmann. Aperture, Nueva York, 1973.

- COLOMA MARTÍN, I. La forma fotográfica. A propósito de la fotografía española desde 1839 a 1939. Universidad de Málaga y Colegio de Arquitectos, Málaga, 1986.

- DUPLESSIS, Y. El surrealismo. Oikos-tau, Vilassar de Mar (Barcelona), 1972.

- GERNSHEIM, H. \& A. Historia gráfica de la fotografía. Omega, Barcelona, 1966. 
- GIMÉNEZ-FRONTÍN, J. L. El surrealismo. En torno al movimiento bretoniano. Montesinos, Barcelona, 1983.

- LARKIN, D. Arte Fantástico. Júcar, Madrid, 1973.

- LARKIN, D. Dalí. Júcar, Madrid, 1974.

- MARCHÁn, S. Del arte objetual al arte de concepto, 1960 - 1974. Alberto Corazón, Madrid, 1974 ( $2^{\mathrm{a}}$ ed.).

- PIERRE, J. El Surrealismo. Aguilar, Madrid, 1969.

- SÁBATO, E. "Carta a Miguel A. Yáñez Polo" en revista Actas de Cultura y Ensayos Fotográficos f/8, $\mathrm{n}^{\circ}$ invierno. f/8 Grupo Fotográfico de Libre Expresión, Sevilla, 1981.

- SANTOS, M. (comisario). Cuatro direcciones. Fotografía contemporánea española 1970 - 1990. Tomo I. Catálogo de la exposición. Lunwerg, Madrid, 1991.

- SCHARF, A. Art and Photography. Penguin Books, Baltimore, 1974.

- TORCZYNER, H. Magritte. Signos e imágenes. Blume, Barcelona, 1978.

- YÁÑEZ POLO, M. A. Diccionario histórico de conceptos, tendencias y estilos fotográficos. (Desde 1839 hasta nuestros días). Sociedad de Historia de la Fotografía Española, Sevilla, 1994.

- YÁÑEZ POLO, M. A. Fotografía latinoamericana: tendencias actuales. Universidad Hispanoamericana Sta. Ma . de La Rábida, Huelva, 1991.

- YÁÑEZ POLO, M. A. Híspalis. La huella de Hipócrates. Real e Ilustre Colegio de Médicos, Sevilla, 1993. 